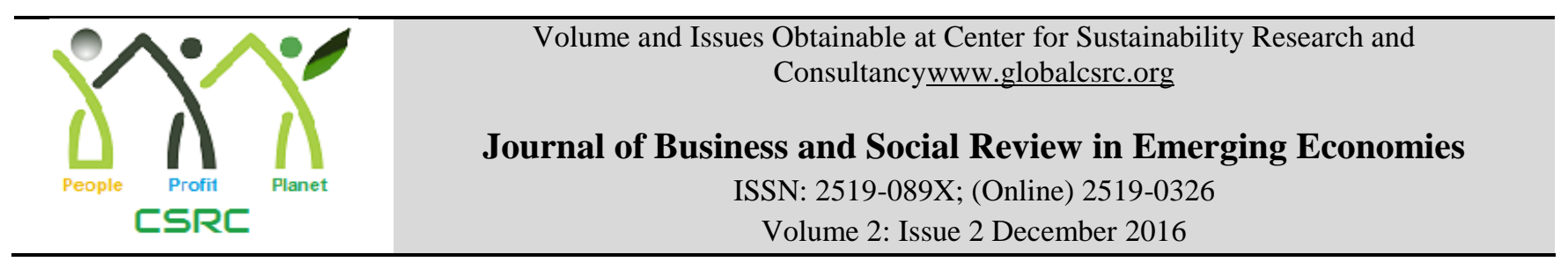

\title{
Impact of Social and Religious Beliefs on SMEs Intention towards Adoption of Formal Finance: A Proposed Model
}

\author{
${ }^{1}$ Rabia Rasheed, ${ }^{2}$ Maria Abdul Rahman \\ ${ }^{1} \mathrm{PhD}$ Scholar, Universiti Utara Malaysia, rabia7862009@live.com \\ ${ }^{2}$ Senior Lecturer,Universiti Utara Malaysia. maria@uum.edu.my
}

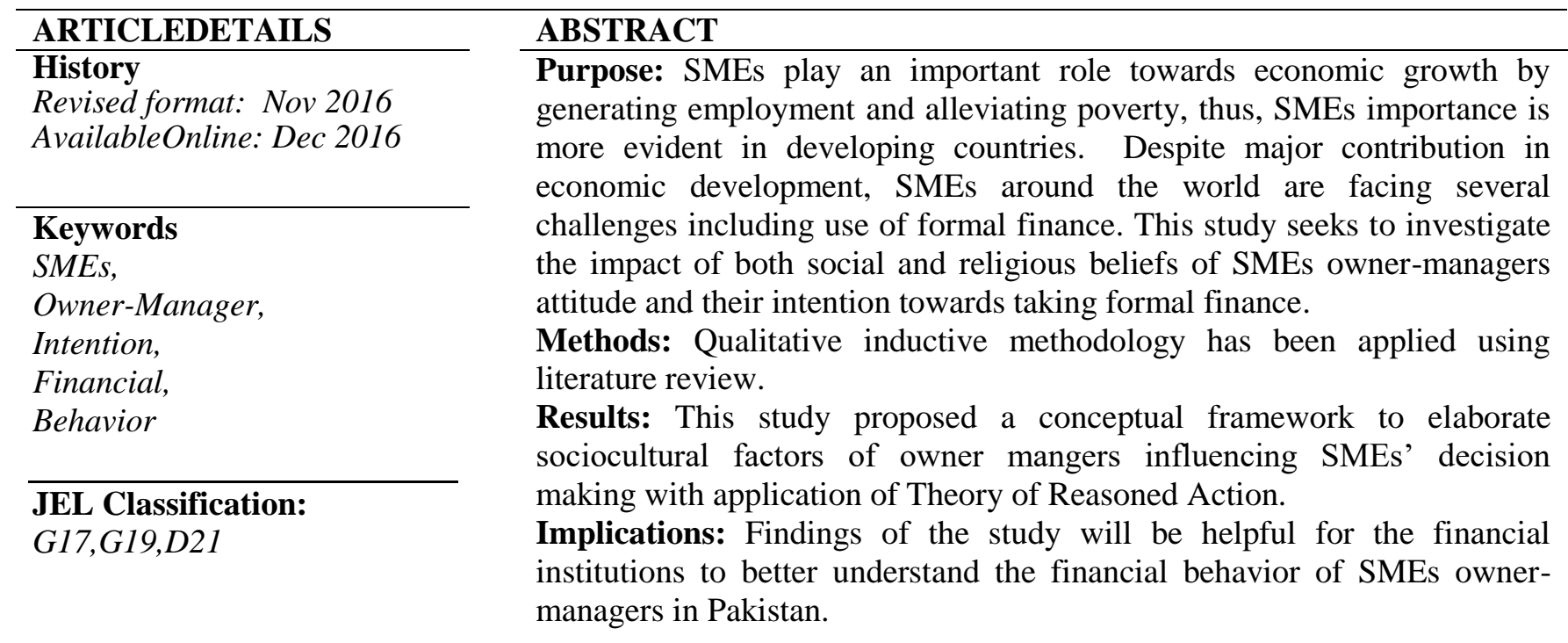

(C) 2016 The authors, under a Creative Commons Attribution-

NonCommercial 4.0

\section{Introduction}

Small and medium enterprises (SMEs) are considered as engines of economic growth and have major input towards sustainable gross domestic product (GDP) across the world. SMEs importance for developing countries' more evident because it recognized as tool of employment generation, poverty alleviation and income generation. Approximately 3 million of SMEs in Pakistan are 90\% of overall businesses, contributing 30\% towards GDP, employing more than $70 \%$ of labor force and $25 \%$ to country total earnings (Robu, 2013; Khan \&Khalique, 2014). Despite of key contributor in economic development SMEs facing several challenges like; corruption, procedural hurdles, inadequate public infrastructure, low level of skill an trainings, technological constraints and access to finance. In Pakistan, it seems difficult for SME owner-managers to fulfill their business financial needs by obtaining formal 
finance as only $11 \%$ of SMEs are well-served, $22 \%$ underserved and $67 \%$ reported as unserved (IFC, 2014). Moreover, only 7\% SMEs using formal finance as compare to India and Bangladesh percentage much higher 33\% and 32\% respectively. This indicates that SME owners' used informal finance more preferably or used their own internal funding's (Khan, 2015).

In Pakistan, social bindings are very strong and people take others opinion seriously, usually, take decisions which are acceptable both socially and religiously. However, it is also understood that religious and social beliefs vary person to person, people who are more religious completely follow Shariah rules or Islamic principles in all of their business matters, on the other hand more social give more weightage to opinion of their family, friends, colleagues and referrals, mostly considered the suggestions of their loved ones and associates before taking any decision (Koropp, Grichnik\&Kellermanns, 2014). Some people lye in between category, business growth and profit always preferable for them. In this particular category population increasing with the passage of time, young and educated owner-managers never take care about social and religious boundaries and concentrate on their business growth. Despite these facts, several factors have an impact on SME owner-managers decisions towards formal finance adoption, though, current study mainly focus on the subjective norms of SMEs owners' in context of Pakistan.

The purpose of this research paper is to investigate impact of social and religious beliefs on SMEs intention towards adoption of formal finance. Specifically, social and religious beliefs studied in an attempt to determine their impact on SME owners' intention combined with attitude and ultimately on their behavior. The research model of study is based on theory of reasoned action (TRA) to investigate SME owners' attitude and behavioral intention towards adoption of formal finance. According to Ajzen and Fishbein, (1980) TRA explicitly embeds subjective norms in attitude formation process. So, towards an object it not only measures the attitude of an individual but also accounts for the role of reference groups in forming and reinforcing such attitudes. This research study supplements prior research and makes contributions to the field as previously studies explored the firm characteristics and ownermanager personal characteristics in context of SMEs financial behavior, though, other social factors still need to explore. Moreover, consumer behavioral theories such as TRA rarely applied by researchers to measure financial behavior of firms owner. By considering this gap, this article aims to develop a conceptual framework for an investigation of social and religious beliefs impact on SMEs intention towards adoption of formal finance in Pakistan.

\section{Literature Review}

Academicians, practitioners and other intellectuals acknowledged that towards economic growth SMEs plays central role. As per statistics of IFC, (2014) report overall 28.7 million formal SMEs are operating globally and approximately 18.6 million in emerging markets. Similarly, in these SMEs around 325.5 million employees are working and in emerging markets SMEs 148.3 million are on job. SMEs predominantly operate in both service and manufacturing sectors and generate employment opportunities for skilled and unskilled individuals (Khan, 2015; SasAruwa, 2013). These businesses not only creating employment, reducing poverty and responsible for income equitable distribution but also significantly contributing to the GDP. In emerging markets, like Pakistan, SMEs are known to catalyze the structural change that translates into macro-economic developments and therefore support sustainable growth.

For Pakistan, SME sector is a key component and essential to boost up economy, these businesses importance cannot be denied for economy revitalization and ensuring inclusive growth in long term. 
Since independence, SMEs role towards economic development is significant and appreciate able as Pakistan's economy majorly relies on SMEs jobs, industrial productivity, export earnings and foreign investments. Approximately $78 \%$ of the industrial labor force employs by SME sector (SBP, 2010), which eventually responsible for training of unskilled labor and helping in skills development. Also fostering the entrepreneurial culture which ultimately translates into cost cutting innovations. As compare to other developing countries, the SME sector in Pakistan still need to achieve its optimal productivity for better contribution in economic activity. However, this sector is facing several obstacles which hinder its productivity and growth, among others, inadequate access to finance is one of the biggest issues.

In Pakistan, to fulfil business financial needs SMEs have access to three main sources of finance 1) formal finance - banks and non-banking financial institutes 2) informal finance - friends and family, advances from customers and credit from suppliers 3) personal savings/ retained earnings.

Over the past few years, due to SMEs poor business conditions which is risky for them and macroeconomic factors banks in Pakistan reducing exposure to SMEs. Yet, banking system of Pakistan still need to build requisite capacity to serve this special sector. According to the June, 2015 Development Finance Review (DFR) of Pakistan, SME outstanding finance was declining till 2013; though, after implementation of revised prudential regulations by State bank of Pakistan (SBP) it increased by $3.19 \%$ till June, 2015. In addition, the SME outstanding finance contribution in GDP was recorded only $1 \%$ which is quite low. Despite this slow increase, banks are main source of formal financing for SMEs in Pakistan and holds $87.1 \%$ of total financial sector. Subsequently, Micro Finance Institutes (MFIs) hold 0.3\%, Development Financial Institutes (DFIs) 1.5\%, NBFCs (leasing companies) $0.3 \%$ and Modarabas, $0.3 \%$, etc (SBP, 2015a; SBP, 2015b) .

Among others, an important issue highlighted by the researchers is that banks are neglecting small enterprises (rejecting 75\% of finance applications) and facilitating medium enterprises (accepting 65\% of applications) which is creating a huge finance gap (Kauser, Durrani, Hussain and Hasan, 2012). It is just because of the informal setups of enterprises which are not able to fulfill the collateral and compliance requirements of banks. Thus, banks show reluctant behavior towards financing to such enterprises. So, these small firms move towards informal financing sources or utilize their personal funding/equity. Even though, the banking infrastructure is developed in Pakistan, SMEs heavily rely on the informal sources of finance and there are several reasons that why SMEs prefer informal financing sources. It includes collateral requirements, lengthy procedures and documentation, borrowing costs etc. To save their time and to avoid other hustles to use informal finance source is quite easy and quick way of getting finance for SMEs (Sherazi et al, 2013; Khan, 2015). It happens mostly between the referrals therefore, without any documentation and requirements SMEs fulfill their business financial needs conveniently. The drawback of informal finance is rate of interest which is much higher than formal finance such as lending in cash by wealthy farmers was charged at $85 \%$, moneylenders $55.2 \%$ and dealers $25.81 \%$ of interest rate.

In financial market the uneven distribution of credit rationing is accredited to constraints on both demand and supply side. On the supply side, lengthy process and procedures of obtaining loans, SME pro policies, under developed legal and financial infrastructure and lack of credit is one of the most important constraint which bar SMEs towards formal financing. On demand side, lack of awareness regarding financial products and services, non-professional attitude of SMEs, lack of management and also firm characteristics such as age, type, size and ownership factors explored by the researchers can create problems in obtaining formal finance. The current study has highlighted the demand side issue, specifically, the impact of social and religious beliefs on SMEs behavioral intention towards adoption of formal finance (Kauser et al, 2012; Nkuah et al, 2013; Sherazi et al, 2012). 


\section{SMEs Behavioral Intention}

The behavioral intention means decision and motivation of an individual towards performing some behavior (Armitage \& Conner, 2001). According to the Ajzen (1991), a person intention to perform a behavior is the determinant of action. Further, stated that among different behaviors, the most immediate predictor of behavior is behavioral intention. Activities performed by the SME owners' are focused by personality traits and behavioral approach are considered as an ancillary action to behavior. In addition, study explained that a person perform some particular action according to his/her intention and researchers can use as behavior proximal measure. However, it doesn't mean that there is always a flawless correlation between behavior and intention, sometime the measure of construct of behavior also required (Fishbein\&Ajzen, 1977; Ajzen\&Fishbein, 1980; Armitage \& Conner, 1998; Francis, et al., 2010). To measure behavioral intention researchers developed consumer behavioral theories, though, empirical evidences with application of consumer behavioral theories to explore the factors effecting financial behavior of SMEs are few.

\section{Social Belief}

Venkatesh et al. (2003) defined social influence as the level of an individual perceives important his/her referrals expect he/she should exercise. It is basically a function of perceived normative beliefs of significant others e.g. family, friends, colleagues, and others referrals weighted by a person motive to comply with each normative belief. Normative norms are function of beliefs which specify a person thoughts regarding acceptance of a particular behavior by associated people or groups (Lada et al., 2009). In these beliefs, social belief reflect the society and cultural influence and provide the instructions regarding acceptable acts, however it vary like in some countries where people are more active socially, social belief have strong impact on an individual behavioral intention. Researchers revealed that social belief is one of the most significant factor towards opting of financial products, an individual decisions towards adoption of different formal finance options influenced by friends and family (Singh et al. 2010; $\mathrm{Yu}, 2012$ ). In Pakistan, social belief have great influence on SME owners' behavioral intention as before taking any decision to take formal finance products they ensure the acceptability socially.

\section{Religious Belief}

Religion is a cause, principle, or a system of beliefs, practices held to with ardor and faith. Moreover, religion is a psychological connection and dominant emotional relationship to things and it persuades people's decisions, goals, motivations, purpose and satisfaction (Kirkpatrick, 2005; Mukhtar \& Butt, 2012). Prior research exposed that religious belief is one of the major factor that effect financial decision making of consumer (Othmen\& Owen, 2001; Tara et al, 2014; Walkhid\&Afrita, 2007). It acts as a cultural lens through which a person decodes the incoming message, thus directly influencing the outcome of marketing communication. So, religion being an integral part of culture influences market researchers, to explore its role in the consumption world (De Run et al. 2010). According to IFC, (2014) report one of the key reasons behind SMEs reluctant behavior in selection of formal financing is religious belief factor, as around 20 to $25 \%$ of SMEs do not use formal finance at all or due to religious beliefs borrow less than $20 \%$ of their requirements. Report further shows that over the past five to six years this sentiment has been growing stronger.

\section{Theoretical Framework}

Theory of reasoned action proposes an individual intent to select or adopt a product based on two main aspects; a person positive/ negative attitude towards behavior and a person perception of social influence or pressure to behave or not (Ajzen\&Fishbein, 1980). In this article, two propositions of TRA are 
important, behavioral intention of SME owners' to choose formal finance and the impact of social and religious beliefs on their behavior. SME owners' attitude towards formal finance might be not positive but the expectation of associated people may affect his/her behavioral intention to choose formal finance. TRA extensively used by scholars to understand the consumer behavior to select wide range of products and services e.g. Islamic and conventional financial products and services, eco products, organic food, online shopping etc. However, very few studies tried to explore the SMEs financial behavior by applying consumer behavior theories. Particularly, the role and effect of subjective norms especially in those countries where consumer attitude intensely influenced by social and religious beliefs. Thus, this article investigate these beliefs as shown in Figure 1.

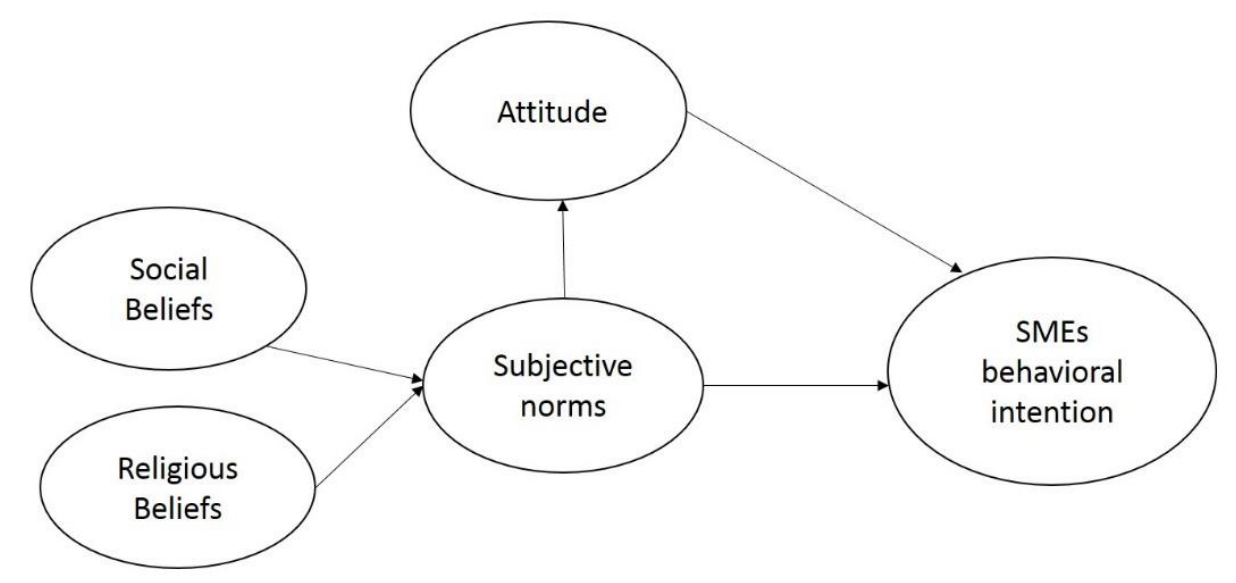

Figure 1.

Research Model

\section{Prepositions}

Preposition1. Attitude positively affect the behavioral intention of SMEs towards adoption of formal finance

Preposition2. Subjective norms positively affect the SMEs behavioral intention towards adoption of formal finance

Preposition3. Social beliefs positively affect the subjective norms of SMEs towards their behavioral intention to adopt formal finance

Preposition4. Religious beliefs positively affect the subjective norms of SMEs towards their behavioral intention to adopt formal finance

\section{Methodology}

According to the Dawson, (2009) research method is the tools used to collect or gather the data. It utilizes several techniques towards the process of data collection and analysis part. Henceforth, there are two aspects of research method one is data collection and the second is analyzing the data. These methods are classified into quantitative and qualitative methods. The technique of collecting data in both 
methods also known as the research instrument.In this study qualitative research design to be followed.

\section{Conclusion}

The proposed model will provide several theoretical and practical contributions towards SMEs financial behavior. Findings of the study will give clear understanding of social and religious beliefs significance towards adoption of formal finance. Moreover, study will be helpful for the financial institutions to better understand the financial needs of SMEs owner-managers as well as for the policy makers to in line their strategies as per SMEs requirements. Additionally, for the government to introduce such policies and schemes through specialized institutes who can help SMEs to fulfill their business financial needs by taking formal finance, in turn, will lead to increased levels of national GDP and employment rate consequently. Theoretically, the proposed model implies that subjective norms influence SMEs intention towards their financial decision making as well have direct impact on SMEs owner-manager attitude. 


\section{References}

Ajzen, I. (1991). The theory of planned behavior. Organizational behavior and human decision processes, 50(2), 179-211.

Ajzen, I., \&Fishbein, M. (1980). Understanding attitudes and predicting social behaviour.

Armitage, C. J., \& Conner, M. (2001). Efficacy of the theory of planned behaviour: A meta-analytic review. British journal of social psychology, 40(4), 471-499.

Aruwa, S. (2013). Financing Options for Small and Medium Scale Enterprises in Nigeria.

Cyril De Run, E., Mohsin Butt, M., Fam, K. S., \& Yin Jong, H. (2010). Attitudes towards offensive advertising: Malaysian Muslims' views. Journal of Islamic Marketing, 1(1), 25-36.

Dawson, C. (2009). Introduction to research methods: A practical guide for anyone undertaking a research project. Hachette UK.

Fishbein, M., \&Ajzen, I. (1977). Belief, attitude, intention, and behavior: An introduction to theory and research.

Francis, J. J., Eccles, M. P., Johnston, M., Walker, A., Grimshaw, J., Foy, R., \&Bonetti, D. (2004). Constructing questionnaires based on the theory of planned behaviour. A manual for health services researchers, 2010, 2-12.

International Finance Corporation, (2014a). Islamic Banking Opportunities Across Small and Medium Enterprises Pakistan, Retrieved from http://www.ifc.org/ 12 December, 2015.

Khan, M. M. (2015a). Sources of finance available for SME sector in Pakistan. International Letters of Social and Humanistic Sciences (ILSHS), 6, 184-194.

Khan, M. W. J., \&Khalique, M. (2014c). An Overview of Small and Medium Enterprises in Malaysia and Pakistan: Past, Present and Future Scenario. Business and Management Horizons, 2(2), 38.

Kirkpatrick, L. A. (2005). Attachment, evolution, and the psychology of religion.Guilford Press.

Koropp, C., Kellermanns, F. W., Grichnik, D., \& Stanley, L. (2014). Financial decision making in family firms: An adaptation of the theory of planned behavior. Family Business Review, 27(4), 307-327.

Kouser, R., Durani, A., Hussain, F. Z., \& Hassan, M. (2012).Investigation of Banker's Lending Criteria to SMEs and Assessment Thereof. International Research Journal of Finance \& Economics, 89, 158-186.

Mukhtar, A., \&Mohsin Butt, M. (2012). Intention to choose Halal products: the role of religiosity. Journal of Islamic Marketing, 3(2), 108-120.

Nkuah, J. K., Tanyeh, J. P., \& Asante, J. (2013). An Assessment of the Role of Financial Institutions in Financing Small and Medium Enterprises (SME's) in Ghana. International Journal of Innovative Research and Development, 2(8).

Othman, A., \& Owen, L. (2001). Adopting and measuring customer service quality (SQ) in Islamic banks: a case study in Kuwait finance house. international journal of Islamic financial services, 3(1), 1-26.

Robu, M. (2013). The Dynamic And Importance Of SMEs In Economy. The USV Annals of Economics and Public Administration, $13(1$ (17)), 84-89.

Sherazi, S. K., Iqbal, M. Z., Asif, M., Rehman, K., \& Shah, S. S. H. (2013).Obstacles to Small and Medium Enterprises in Pakistan.Principal Component Analysis Approach. Middle-East Journal of Scientific Research, ISSN 1990,9233, 1325-1334.

Singh, S., Srivastava, V., \& Srivastava, R. K. (2010). Customer acceptance of mobile banking: A conceptual framework. Sies journal of management,7(1), 55.

State Bank of Pakistan,(2010). State Bank of Pakistan Policy and Regulation. Karachi: State Bank of Pakistan.

State Bank of Pakistan,(2015a). National Financial Inclusion Strategy Pakistan. Karachi: State Bank of Pakistan. 
State Bank of Pakistan,(2015b). Quarterly SME Finance Review: Infrastructure, Housing \& SME Finance Department. Karachi: State Bank of Pakistan.

Tara, N., Irshad, M., Khan, M. R., Yamin, M., \&Rizwan, M. (2014). Factors Influencing Adoption of Islamic Banking: A Study from Pakistan. Journal of Public Administration and Governance, 4(3), 352-367.

Venkatesh, V., Morris, M. G., Davis, G. B., \& Davis, F. D. (2003). User acceptance of information technology: Toward a unified view. MIS quarterly, 425-478.

WakhidS.C.,\&Efrita S. (2007). Adapting Islamic Banks' CARTER model: an empirical study in Riau's Syariah Banks, Indonesia.

Yu, C. S. (2012). Factors affecting individuals to adopt mobile banking: Empirical evidence from the UTAUT model. Journal of Electronic Commerce Research, 13(2), 104. 